\title{
Effect of dietary macronutrients on postprandial incretin hormone release and satiety in obese and normal-weight women
}

\author{
Tomasz Wikarek ${ }^{1}$, Jerzy Chudek ${ }^{2}$, Aleksander Owczarek ${ }^{3}$ and Magdalena Olszanecka-Glinianowicz ${ }^{1 *}$ \\ ${ }^{1}$ Health Promotion and Obesity Management Unit, Department of Pathophysiology, Medical University of Silesia, \\ Medyków Street 18, Katowice 40-752, Poland \\ ${ }^{2}$ Pathophysiology Unit, Department of Pathophysiology, Medical University of Silesia, Katowice, Poland \\ ${ }^{3}$ Division of Statistics, Department of Instrumental Analysis, Medical University of Silesia, Sosnowiec, Poland
}

(Submitted 2 November 2012 - Final revision received 11 June 2013 - Accepted 11 June 2013 - First published online 6 August 2013)

\section{Abstract}

The aim of the present study was to assess the effect of dietary macronutrients on postprandial incretin responses and satiety and hunger sensation in obese and normal-weight women. A total of eleven obese and nine normal-weight women were recruited for the assessment of plasma concentrations of glucagon-like peptide-1 (GLP-1), glucose-dependent insulinotropic polypeptide (GIP) and insulin and the sensation of satiety and hunger using a visual analogue scale before and during a $6 \mathrm{~h}$ period after administration of three different macronutrient test meals. The $\mathrm{AUC}_{\text {total GLP-1 }}$ and $\mathrm{AUC}_{\text {total GIP }}$ values were decreased in obese women after the consumption of a fatty meal and all the test meals, respectively. However, the $\mathrm{AUC}_{\text {total insulin }}$ value after a carbohydrate meal was greater in the obese group. The $\mathrm{AUC}_{\text {total satiety }}$ value was decreased only after the intake of the protein meal in obese women when compared with normal-weight women. After the consumption of the fatty meal, a significant positive correlation between maximum satiety sensation and the $\mathrm{AUC}_{\mathrm{totalGL}-1} \mathrm{Value}_{\text {in }}$ the

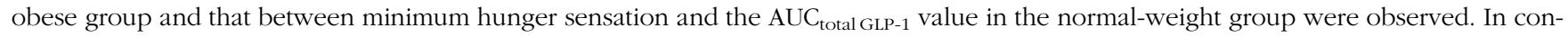
clusion, the findings of the present study suggest that: (1) satiety sensation after consumption of carbohydrate and protein meals in the obese group is related to the postprandial insulin response, while after consumption of a fatty meal, it is related to the postprandial GLP-1 release; (2) the postprandial GIP response does not influence the sensation of satiety and hunger; (3) the reduced GLP-1 release after the intake of a fatty meal in obese individuals may explain impaired satiety sensation; (4) the impaired postprandial GIP response is not related to the consumption of macronutrients and may be the early indicator of incretin axis dysfunction in obese women.

Key words: Macronutrients: Insulin: Glucagon-like peptide-1: Glucose-dependent insulinotropic polypeptide: Satiety

Obesity is an important public health problem worldwide. Despite many initiatives, the number of obese people continues to grow. Currently, there is an intensive debate concerning the most effective management of obesity using dietary macronutrient composition (high carbohydrate, high fat or high protein). However, the results of a 2-year followup study has revealed that reduced-energy diets result in clinically meaningful weight loss regardless of macronutrient composition $^{(1)}$. Moreover, in addition to the effectiveness of the diet, the impact of macronutrients on general health and postprandial satiety is even more important for obesity management.

Dietary manipulations that prolong postprandial sensation of satiety can improve adherence to a restricted-energy diet and long-term outcomes. Hunger ratings and subsequent food intakes in normal-weight subjects have been shown to be reduced following the intake of a protein meal, compared with consumption of carbohydrate and fat meals ${ }^{(2)}$. This may be related to higher postprandial circulating glucagon-like peptide-1 (GLP-1) and insulin levels $1-3 \mathrm{~h}$ after ingestion of whey protein compared with glucose observed in normalweight and obese men ${ }^{(3)}$. It has also been shown that carbohydrates affecting lower glycaemic and insulinaemic responses prolong satiety sensation ${ }^{(4)}$. The results of a recently published study has also shown that the intake of milk induces greater subjective fullness and less hunger as well as leads to higher GLP-1 and glucose-dependent insulinotropic polypeptide (GIP) concentrations than regular cola intake ${ }^{(5)}$.

The results of previously published studies have revealed an abnormal, attenuated postprandial GLP-1 response in obese subjects, with its improvement following weight reduction ${ }^{(6)}$. There is convincing evidence that GLP-1 is one of the mealinduced satiety response mediators. GLP-1 inhibits gastric emptying $^{(7)}$ and the activity of the central nervous system

Abbreviations: E\%, percentage of energy; GIP, glucose-dependent insulinotropic polypeptide; GLP-1, glucagon-like peptide-1.

* Corresponding author: Professor M. Olszanecka-Glinianowicz, email magols@esculap.pl 
involved in the regulation of satiety ${ }^{(8)}$. Similar effects have been observed after administration of liraglutide, a GLP-1 analogue ${ }^{(9)}$. Therefore, GLP-1 analogues are a new class of drugs potentially useful in obesity management. On the other hand, as mentioned above, dietary manipulations may improve the postprandial GLP-1 release and increase adherence to the diet recommendation and improve the effectiveness of the diet. Moreover, the increase in postprandial GLP-1 release is followed by the improvement of glucose homeostasis (incretin action of GLP-1) ${ }^{(10)}$.

There is a growing body of evidence that GIP is the second key hormone of the incretin axis, involved in the stimulation of postprandial insulin secretion ${ }^{(10)}$ and the regulation of satiety. However, in contrast to GLP-1, the postprandial GIP level is inversely related to the subsequent feeling of satiety ${ }^{(11,12)}$. In addition, a higher postprandial GIP response after ingestion of a high-fat test meal in post-obese women compared with normal-weight women has been found ${ }^{(11)}$. Thus, it has been suggested that GIP stimulates hunger sensation and its supranormal release participates in obesity development ${ }^{(11)}$. This hypothesis is partially supported by the results obtained by Daousi et $a l .{ }^{(13)}$, revealing that healthy normal-weight men but not obese type 2 diabetic subjects have reported higher hunger scores during GIP infusion compared with placebo.

The above-described data were obtained from studies regarding protein or sugar drink administered before consumption of a high-fat or mixed meal. However, there are no data concerning postprandial activity of the incretin axis, insulin secretion and satiety or hunger sensation after ingestion of high-carbohydrate, high-protein and high-fat test meals that are likely to be normally consumed. Moreover, there is a lack of studies assessing the differences between obese and normal-weight subjects in the effect of various macronutrients on the incretin axis and satiety or hunger sensation.

Therefore, the aim of the present study was to assess the effect of dietary macronutrients on postprandial incretin responses and satiety and hunger sensation in obese and normal-weight women.

\section{Experimental methods}

A total of twenty young women (eleven obese without comorbidities and nine healthy normal weight) with a stable weight during at least a 3-month period and not pharmacologically treated were included in the present study. Subjects suffering from Cushing's syndrome, thyroid dysfunctions, hyperandrogenism, type 1 and 2 diabetes and any other diseases including gastrointestinal diseases as well as bariatric surgery procedures were excluded. Additional exclusion criteria were smoking and alcohol consumption. The present study was conducted according to the guidelines laid down in the Declaration of Helsinki, and all procedures involving human subjects were approved by the Bioethical Committee of Medical University of Silesia. The study was conducted after obtaining written informed consent from each participant.

All of the participants were tested within 2 and $6 \mathrm{~d}$ of the menstrual cycle. At baseline, anthropometric measurements (body mass, height and waist circumference) were performed and BMI was calculated according to the standard formula: body mass $(\mathrm{kg}) /$ height $\left(\mathrm{m}^{2}\right)$. In addition, body composition was assessed by bioimpedance analysis using the Bodystat 1500 analyser. The characteristics of the study groups are presented in Table 1.

\section{Study protocol}

Subjects arrived using motorised transportation at the Health Promotion and Obesity Management Unit at 08.30 hours with $1 \mathrm{~d}$ intervals between the test meals. After a $16 \mathrm{~h}$ overnight fast, the subjects were served carbohydrate, protein and fatty meals at 09.00 hours on the 1st, 3rd and 5th day of the study.

The solid test meals had the same mass and volume but different energy contents. The carbohydrate meal with $874 \mathrm{~kJ}$ $(209 \mathrm{kcal})$ of energy consisted of $150 \mathrm{~g}$ rice and $50 \mathrm{~g}$ stewed apple. This meal consisted of $6 \mathrm{E} \%$ (percentage of energy) protein, $1 \mathrm{E} \%$ fat and $93 \mathrm{E} \%$ carbohydrates, with an energy density of $4.39 \mathrm{~kJ} / \mathrm{g}(1.05 \mathrm{kcal} / \mathrm{g})$. The protein meal with $749 \mathrm{~kJ}$ ( $179 \mathrm{kcal})$ of energy composed of $150 \mathrm{~g}$ low-fat white cheese and $50 \mathrm{~g}$ of $2 \%$ yogurt. This meal consisted of $72 \mathrm{E} \%$ protein, $9 \mathrm{E} \%$ fat and $19 \mathrm{E} \%$ carbohydrates, with an energy density of $3.72 \mathrm{~kJ} / \mathrm{g}(0.89 \mathrm{kcal} / \mathrm{g})$. The fatty meal with $3075 \mathrm{~kJ}(735 \mathrm{kcal})$ of energy consisted of $100 \mathrm{~g}$ mackerel, $50 \mathrm{~g}$ mayonnaise and $50 \mathrm{~g}$ egg yolk. This meal consisted of $15 \mathrm{E} \%$ protein, $84 \mathrm{E} \%$ fat and $1 \mathrm{E} \%$ carbohydrates, with an energy density of $15.35 \mathrm{~kJ} / \mathrm{g}(3.67 \mathrm{kcal} / \mathrm{g})$. The test meals were prepared directly before serving to the subjects and were administered in the same dish. The consumption of the test meals was controlled by a dietitian. The test meals were not served in random order. Each subject first consumed the carbohydrate meal, second the protein meal and finally the fatty meal.

A computer database of foods from the National Food and Nutrition Institute (Diet 4.0, Polish Food Tables 2005) was used to calculate the energy and macronutrient composition of the test meals.

During the $6 \mathrm{~h}$ period after ingestion of the test meals, the subjects did not consume other products, and drank no other fluid than $30 \mathrm{ml}$ of still mineral water.

Venous blood samples $(10 \mathrm{ml})$ were withdrawn from the subjects and sensation of satiety and hunger was measured using a $0-100 \mathrm{~mm}$ visual analogue scale in the fasting state and at 15, 60, 120, 180, 240, 300 and 360 min after consumption of the test meals. For analysis of the appetite questionnaire, the distance between the left end of the scale and each mark was measured $(\mathrm{mm})$. The mean response to 'How hungry do you feel?/How much food would you like to eat now?/How strong do you like eating?' and 'How satiating do you feel at the moment?/How satisfied do you feel?/ How full do you feel?' was calculated for each subject and used for subsequent analysis ${ }^{(14)}$.

\section{Laboratory procedures}

Venous blood samples were collected directly into Vacutainer tubes (Becton Dickinson) according to the manufacturer's recommendations for the use of their kits. Aliquots of serum and plasma samples were frozen at $-70^{\circ} \mathrm{C}$. 
Table 1. Characteristics of the study groups

(Mean values and standard deviations)

\begin{tabular}{|c|c|c|c|c|c|}
\hline & \multicolumn{2}{|c|}{ Obese $(n 11)$} & \multicolumn{2}{|c|}{$\begin{array}{l}\text { Normal weight } \\
(n 9)\end{array}$} & \multirow[b]{2}{*}{$P$} \\
\hline & Mean & SD & Mean & SD & \\
\hline Age (years) & 28.9 & $5 \cdot 7$ & $23 \cdot 3$ & $5 \cdot 3$ & $<0.05$ \\
\hline Body mass $(\mathrm{kg})$ & $90 \cdot 9$ & 11.5 & $59 \cdot 1$ & $7 \cdot 3$ & $<0.001$ \\
\hline BMI $\left(\mathrm{kg} / \mathrm{m}^{2}\right)$ & $33 \cdot 3$ & 4.4 & $22 \cdot 6$ & $2 \cdot 0$ & $<0.001$ \\
\hline Body fat (\%) & $44 \cdot 9$ & $5 \cdot 3$ & $29 \cdot 2$ & 4.0 & $<0.001$ \\
\hline Body fat (kg) & $40 \cdot 6$ & 8.5 & $17 \cdot 3$ & $3 \cdot 0$ & $<0.001$ \\
\hline Free fat mass (\%) & $55 \cdot 1$ & $5 \cdot 3$ & $70 \cdot 8$ & $2 \cdot 9$ & $<0.001$ \\
\hline Free fat mass $(\mathrm{kg})$ & $50 \cdot 3$ & 4.7 & $41 \cdot 8$ & $5 \cdot 1$ & $<0.001$ \\
\hline Waist circumference $(\mathrm{cm})$ & $104 \cdot 0$ & $8 \cdot 2$ & $74 \cdot 8$ & $2 \cdot 2$ & $<0.001$ \\
\hline \multicolumn{6}{|l|}{ Fasting serum glucose (mg/l) } \\
\hline Before carbohydrate meal administration & 841 & 75 & 848 & 98 & NS \\
\hline Before protein meal administration & 844 & 62 & 799 & 98 & NS \\
\hline Before fatty meal administration & 838 & 66 & 836 & 63 & NS \\
\hline \multicolumn{6}{|l|}{ Fasting serum TAG (mg/l) } \\
\hline Before carbohydrate meal administration & 790 & 261 & 621 & 207 & $<0.01$ \\
\hline Before protein meal administration & 753 & 290 & 540 & 176 & $<0.01$ \\
\hline Before fatty meal administration & 854 & 414 & 637 & 222 & $<0.01$ \\
\hline \multicolumn{6}{|l|}{ Fasting serum insulin $(\mu \mathrm{IU} / \mathrm{ml})$} \\
\hline Before carbohydrate meal administration & $6 \cdot 1$ & $2 \cdot 4$ & $5 \cdot 9$ & $2 \cdot 7$ & NS \\
\hline Before protein meal administration & $5 \cdot 6$ & 1.9 & 4.7 & 3.6 & NS \\
\hline Before fatty meal administration & $4 \cdot 0$ & 1.5 & $4 \cdot 1$ & 1.6 & NS \\
\hline \multicolumn{6}{|l|}{ Fasting plasma GLP-1 (ng/ml) } \\
\hline Before carbohydrate meal administration & 0.5 & 0.1 & 0.5 & 0.1 & NS \\
\hline Before protein meal administration & 0.5 & 0.1 & 0.5 & 0.1 & NS \\
\hline Before fatty meal administration & 0.5 & 0.2 & 0.5 & 0.1 & NS \\
\hline \multicolumn{6}{|l|}{ Fasting plasma GIP (ng/ml) } \\
\hline Before carbohydrate meal administration & $2 \cdot 4$ & $2 \cdot 1$ & $3 \cdot 1$ & $1 \cdot 0$ & NS \\
\hline Before protein meal administration & $2 \cdot 5$ & 1.6 & $2 \cdot 5$ & 1.8 & NS \\
\hline Before fatty meal administration & 1.8 & 0.8 & $2 \cdot 5$ & 0.5 & NS \\
\hline \multicolumn{6}{|l|}{ Fasting satiety sensation (mm) } \\
\hline Before carbohydrate meal administration & 42 & 22 & 15 & 9 & $<0.01$ \\
\hline Before protein meal administration & 38 & 36 & 25 & 17 & $<0.01$ \\
\hline Before fatty meal administration & 33 & 33 & 15 & 12 & $<0.01$ \\
\hline \multicolumn{6}{|l|}{ Fasting hunger sensation (mm) } \\
\hline Before carbohydrate meal administration & 32 & $2 \cdot 2$ & 51 & 14 & $<0.01$ \\
\hline Before protein meal administration & 44 & 3.6 & 61 & 22 & $<0.01$ \\
\hline Before fatty meal administration & 50 & 3.5 & 78 & 17 & $<0.01$ \\
\hline
\end{tabular}

GLP-1, glucagon-like peptide-1; GIP, glucose-dependent insulinotropic polypeptide.

Plasma glucose and TAG levels were estimated by colorimetric methods using commercially available test kits (Roche). Serum insulin concentrations were measured by RIA (Diagnostic Product Corporation) with a lower limit of sensitivity of $1.2 \mu \mathrm{IU} / \mathrm{ml}(8.6 \mathrm{pmol} / \mathrm{l})$ and intra- and inter-assay $\mathrm{CV}$ of $5 \cdot 0$ and $10 \cdot 0 \%$, respectively. Plasma GLP-1 and GIP levels were assessed by ELISA (Phoenix Pharmaceuticals, Inc.) with a lower limit of sensitivity of 0.11 and $0.41 \mathrm{ng} / \mathrm{ml}$, respectively, and intra- and inter-assay CV of 5.0-10 and $15 \cdot 0 \%$, respectively.

\section{Statistical analysis}

All statistical analyses were performed using Statistica 9.0 (StatSoft) and $\mathrm{R}$ software (University of Wroclaw). Results are presented as means and standard deviations. The distribution of variables was evaluated by the Shapiro-Wilk test. The homogeneity of variances was assessed by the Levene test. For comparison of data between subjects and controls, Student's $t$ test for independent data was used in the case of a normal distribution or after normalisation. In order to assess changes in the sensation of satiety and hunger as well as hormone concentrations over time after ingestion of the test meals, two-way ANOVA with repeated measures and analysis of contrasts were used. In order to estimate the time to achieve the maximum sensation of satiety and hunger during the test, cubic spline interpolation was used. For each of the profiles, interpolation function was matched and on the basis of which the peak value was determined. For the energy-adjusted assessment of the responses, we divided each subject's value of AUC by the energy of the test meal in kcal (according to group and type of the meal). Correlations between the analysed variables were determined either with Pearson's correlation coefficient in the case of normally distributed data or with Spearman's range correlation coefficient for other data. All tests were two-tailed, with $P<0.05$ considered as statistically significant.

\section{Results}

Fasting serum glucose, TAG and insulin levels as well as plasma GLP-1 and GIP levels were similar before ingestion of all the test meals in both study groups (Table 1 ). 
Fasting serum glucose and plasma GLP-1 levels did not differ between the obese and normal-weight women, while fasting serum TAG concentrations were higher in obese subjects. Fasting serum insulin level was significantly higher in obese subjects but not in normal-weight subjects during consumption of the carbohydrate test meal than when the fatty test meal was administered. In addition, plasma GIP level was lower in obese subjects than in normal-weight subjects during the days when the carbohydrate and fatty test meals were served (Table 1).

Fasting satiety sensation in both study groups was similar and significantly higher in the obese group than in the normal-weight group during all the study days (Table 1).

Fasting hunger sensation in the obese group was similar on all the study days when the test meals were administered, while fasting hunger sensation in the normal-weight group was significantly higher on the day when the fatty meal was served than on the day of the administration of the carbohydrate meal (78 (SD 17) v. 51 (SD 14) mm; P<0.05). Throughout the study days, fasting hunger sensation was lower in the obese group than in the normal-weight group (Table 1).

\section{Effect of the test meals on satiety and hunger sensation}

The $\mathrm{AUC}_{\text {satiety }}$ value in the obese group was significantly higher after ingestion of the fatty test meal compared with after the protein and carbohydrate test meals. However, the $\mathrm{AUC}_{\text {satiety }}$ value in the normal-weight group was higher after consumption of the fatty test meal than after the carbohydrate, but not protein, test meal (Table 2).

The $\mathrm{AUC}_{\text {satiety }}$ value was similar after consumption of the carbohydrate and fatty test meals in the obese and normal-weight groups. However, after ingestion of the protein meal, the $\mathrm{AUC}_{\text {satiety }}$ value was significantly lower in the obese group than in the normal-weight group $(P<0 \cdot 05$; Fig. 1$)$.

There were no differences in the time to achieve the mean maximum sensation of satiety after ingestion of the carbohydrate, protein and fatty test meals between the obese and normal-weight groups (40 (SD 34) v. 36 (SD 18) min; 36 (SD 25) v. 29 (SD 9) $\mathrm{min}$ and 34 (SD 18) v. 34 (SD 17) min, respectively). The time to achieve the mean maximum satiety after ingestion of the carbohydrate, protein and fatty test meals was similar in both groups (40 (SD 34) v. 36 (SD 25) v. 34 (SD 18) min and 36 (SD 18) v. 29 (SD 9) v. 34 (SD 17) min, respectively).

The $\mathrm{AUC}_{\text {hunger }}$ value in both groups did not differ significantly after ingestion of the carbohydrate, protein and fatty test meals (Table 2).

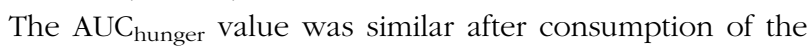
carbohydrate and fatty test meals in the obese and normalweight groups, while it was significantly higher after ingestion of the protein meal in the obese group $(P<0 \cdot 05$; Fig. 2$)$.

There were no differences in the time to achieve the minimum sensation of hunger after ingestion of the protein and fatty test meals between the obese and normal-weight groups (25 (SD 7) v. 28 (SD 10) $\mathrm{min}$ and 29 (SD 15) $\min v .30$ (SD 12) min, respectively), while the time to achieve the minimum sensation of hunger after consumption of the carbohydrate test meal was significantly shorter in the obese group (19 (SD 13) v. 51 (sD 26) min, $P<0 \cdot 001$ ). Additionally, in the normal-weight group only, the minimum hunger sensation after carbohydrate was significantly longer than after protein and fatty test meal ingestion (51 (SD 26) v. 28

Table 2. Effect of the test meals on the sensation of satiety and hunger as well as the levels of hormone release (AUC value) in obese ( $n$ 11) and normal-weight $(n 9)$ subjects

(Mean values and standard deviations)

\begin{tabular}{|c|c|c|c|c|c|c|c|c|c|c|c|c|}
\hline & \multicolumn{6}{|c|}{ Row data } & \multicolumn{6}{|c|}{ Energy-adjusted data } \\
\hline & \multicolumn{2}{|c|}{ Carbohydrate } & \multicolumn{2}{|c|}{ Protein } & \multicolumn{2}{|c|}{ Fatty } & \multicolumn{2}{|c|}{ Carbohydrate } & \multicolumn{2}{|c|}{ Protein } & \multicolumn{2}{|c|}{ Fatty } \\
\hline & Mean & SD & Mean & SD & Mean & SD & Mean & $\mathrm{SD}$ & Mean & SD & Mean & SD \\
\hline & \multicolumn{6}{|c|}{ Satiety $(\mathrm{mm} \times \mathrm{h})$} & \multicolumn{6}{|c|}{ Satiety $(\mathrm{mm} \times \mathrm{h} / \mathrm{kcal})$} \\
\hline Obese & $1648 \dagger$ & 774 & 2052 & 859 & 2595 & 712 & $7 \cdot 9$ & $3 \cdot 7$ & $11 \cdot 5^{\star \star \star}$ & $4 \cdot 8$ & 3.7 & $1 \cdot 0$ \\
\hline \multirow[t]{2}{*}{ Normal weight } & $1035+\dagger$ & 538 & $1209^{*}$ & 446 & 2140 & 833 & 4.9†††‡ & $2 \cdot 6$ & $6 \cdot 8^{\star \star *}$ & $2 \cdot 5$ & $3 \cdot 1$ & $1 \cdot 2$ \\
\hline & \multicolumn{6}{|c|}{ Hunger $(\mathrm{mm} \times \mathrm{h})$} & \multicolumn{6}{|c|}{ Hunger $(\mathrm{mm} \times \mathrm{h} / \mathrm{kcal})$} \\
\hline Obese & 1329 & 749 & 706 & 576 & 975 & 582 & 6.4††† & $3 \cdot 6$ & $5 \cdot 5^{\star \star \star}$ & $3 \cdot 3$ & $1 \cdot 0$ & 0.8 \\
\hline \multirow[t]{2}{*}{ Normal weight } & 1245 & 894 & 1737 & 605 & 2046 & 641 & 8.3††† & 2.9 & $11 \cdot 5^{\star \star \star}$ & $3 \cdot 6$ & $1 \cdot 8$ & $1 \cdot 3$ \\
\hline & \multicolumn{6}{|c|}{ Insulin $(\mu \mathrm{IU} \times \mathrm{h} / \mathrm{ml})$} & \multicolumn{6}{|c|}{ Insulin $(\mu \mathrm{IU} \times \mathrm{h} / \mathrm{ml}$ per kcal $)$} \\
\hline Obese & 4869† & 2784 & $3981^{*}$ & $2171^{\prime}$ & 2349 & 1004 & 23.3††† & $13 \cdot 3$ & $22 \cdot 2^{\star \star \star}$ & $12 \cdot 1$ & $3 \cdot 2$ & 1.4 \\
\hline \multirow[t]{2}{*}{ Normal weight } & $3929 \dagger$ & 1719 & 3046 & 1406 & 2231 & 509 & $18 \cdot 8 \dagger † \dagger$ & $8 \cdot 2$ & $17 \cdot 0^{\star * *}$ & $7 \cdot 8$ & $3 \cdot 0$ & 0.7 \\
\hline & \multicolumn{6}{|c|}{ GLP-1 $(\mathrm{ng} \times \mathrm{h} / \mathrm{ml})$} & \multicolumn{6}{|c|}{ GLP-1 $(\mathrm{ng} \times \mathrm{h} / \mathrm{ml}$ per kcal) } \\
\hline Obese & 167 & 32 & 172 & 35 & 159 & 44 & 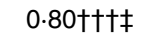 & $0 \cdot 15$ & $0.96^{\star \star \star}$ & 0.19 & 0.22 & 0.06 \\
\hline \multirow[t]{2}{*}{ Normal weight } & 180 & 40 & 201 & 42 & 214 & 55 & $0 \cdot 86+† \dagger$ & $0 \cdot 19$ & $1 \cdot 12^{\star \star \star}$ & $0 \cdot 23$ & 0.29 & 0.07 \\
\hline & \multicolumn{6}{|c|}{ GIP $(\mathrm{ng} \times \mathrm{h} / \mathrm{ml})$} & \multicolumn{6}{|c|}{ GIP $(\mathrm{ng} \times \mathrm{h} / \mathrm{ml}$ per kcal) } \\
\hline Obese & 1238 & 615 & $1051^{*}$ & 444 & 1596 & 689 & 5.92††† & 2.94 & $5 \cdot 87^{\star \star \star}$ & 2.48 & $2 \cdot 17$ & 0.94 \\
\hline Normal weight & $1394 \dagger$ & 454 & $1438^{*}$ & 388 & 1967 & 573 & 6.67††† & $2 \cdot 17$ & $8 \cdot 03^{* \star *}$ & $2 \cdot 17$ & 2.68 & 0.78 \\
\hline
\end{tabular}

GLP-1, glucagon-like peptide-1; GIP, glucose-dependent insulinotropic polypeptide.

Mean value was significantly different from that of the fatty meal: * $P<0.05,{ }^{\star \star *} P<0.001$.

Mean value was significantly different from that of the fatty meal: $\dagger P<0.05, \dagger \dagger P<0.01, \dagger \dagger \dagger P<0.001$.

Mean value was significantly different from that of the protein meal: $\ddagger P<0.05$. 

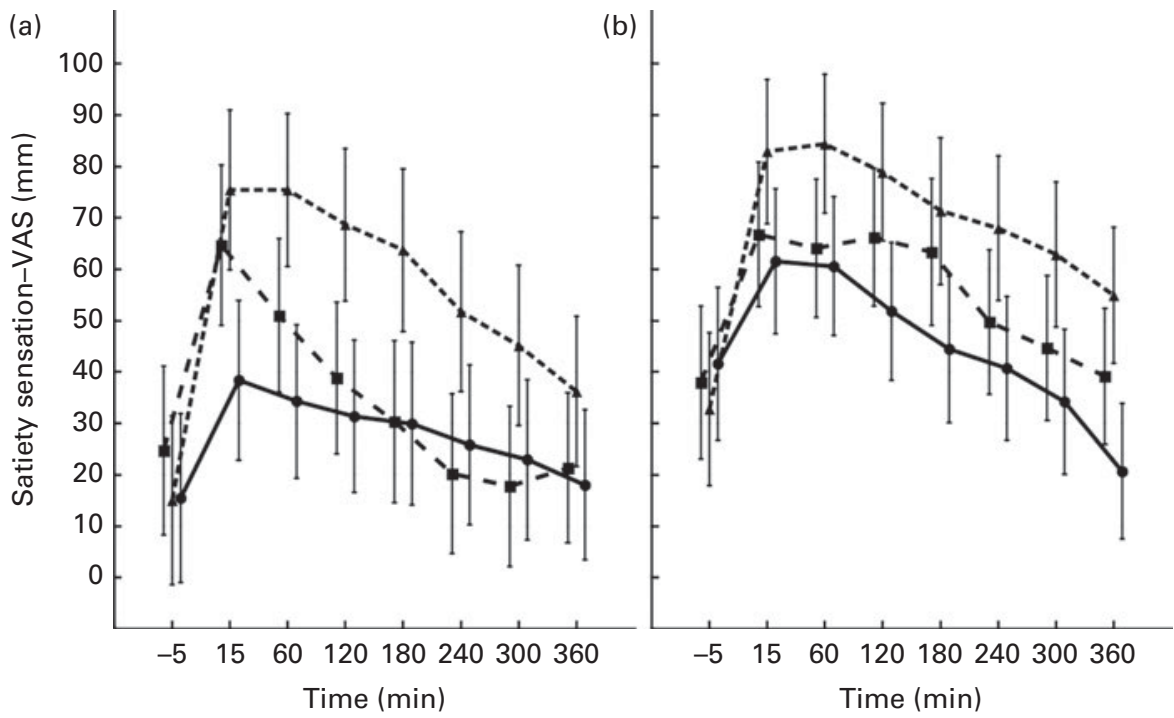

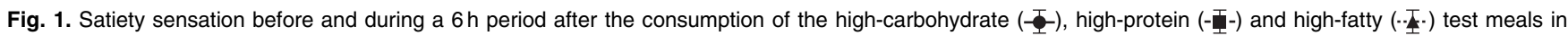
(a) normal-weight subjects $(n 9)$ and (b) obese subjects ( $n 11)$. VAS, visual analogue scale.

(SD 10) $\mathrm{min} ; P<0.05$ and 51 (SD 26) v. 30 (SD 12) $\mathrm{min} ; P<0 \cdot 05$ respectively).

The analysis of the changes in postprandial sensation of satiety and hunger based on consumed energy did not affect the results.

\section{Effect of the test meals on the levels of hormone release}

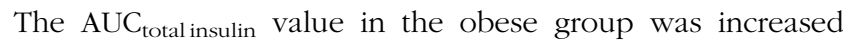
after consumption of the protein and carbohydrate test meals compared with the fatty test meal; however, it was similar after ingestion of the protein and carbohydrate test meals. While in the normal-weight group, the $\mathrm{AUC}_{\text {total insulin }}$ value was increased only after the ingestion of the carbohydrate test meal compared with the fatty test meal and did not differ after the intake of the carbohydrate and protein test meals as well as the protein and fatty test meals (Table 2).
However, the $\mathrm{AUC}_{\text {total insulin value was significantly increased }}$ in obese women compared with normal-weight women only after ingestion of the carbohydrate test meal $(P<0 \cdot 05$; Fig. 3).

There were no significant differences in the values of AUC $_{\text {total GLP-1 }}$ after ingestion of the carbohydrate and protein test meals in relation to the fatty test meal in both obese and normal-weight groups (Table 2). The $\mathrm{AUC}_{\text {total GLP-1 value was }}$ significantly decreased in obese women than in normalweight women only after ingestion of the fatty test meal $(P<0.05$; Fig. 4).

In both groups, the $\mathrm{AUC}_{\text {total GIP }}$ values were similar after consumption of the carbohydrate and protein test meals. Moreover, there were no differences between the values of $\mathrm{AUC}_{\text {total GIP }}$ after ingestion of the carbohydrate and fatty test meals in obese women. While in the normal-weight group,
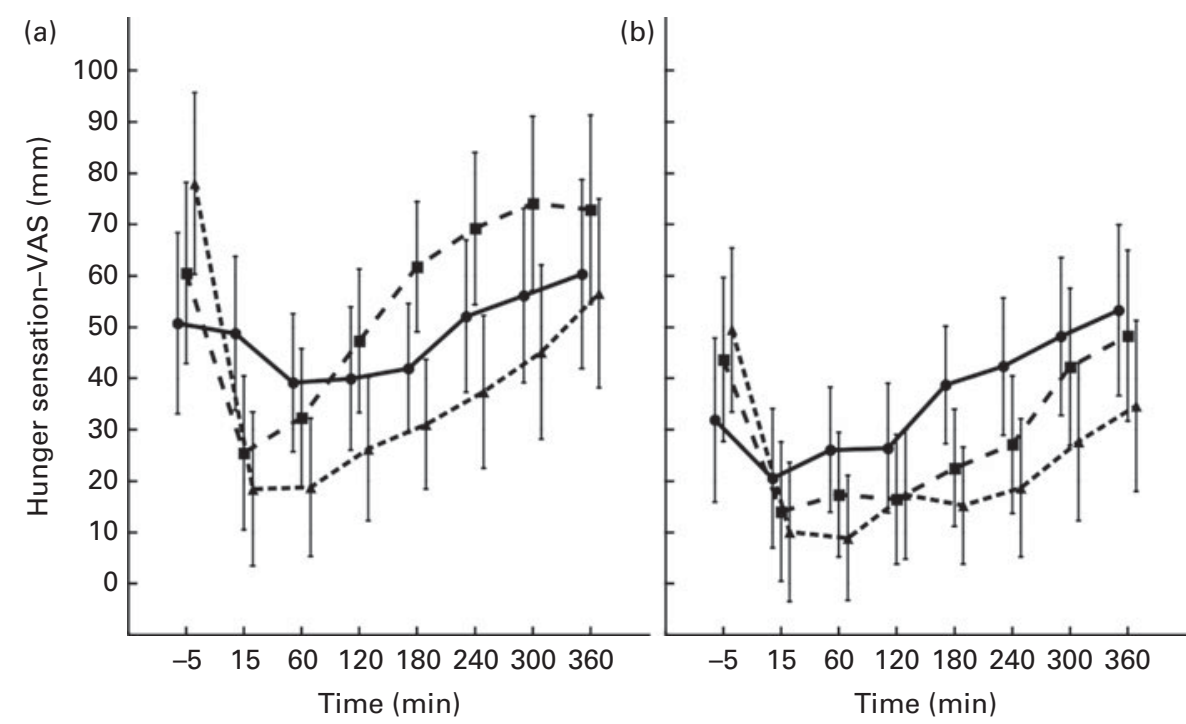

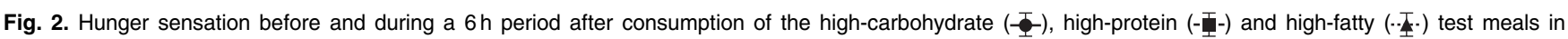
(a) normal-weight subjects $(n 9)$ and (b) obese subjects $(n 11)$. VAS, visual analogue scale. 

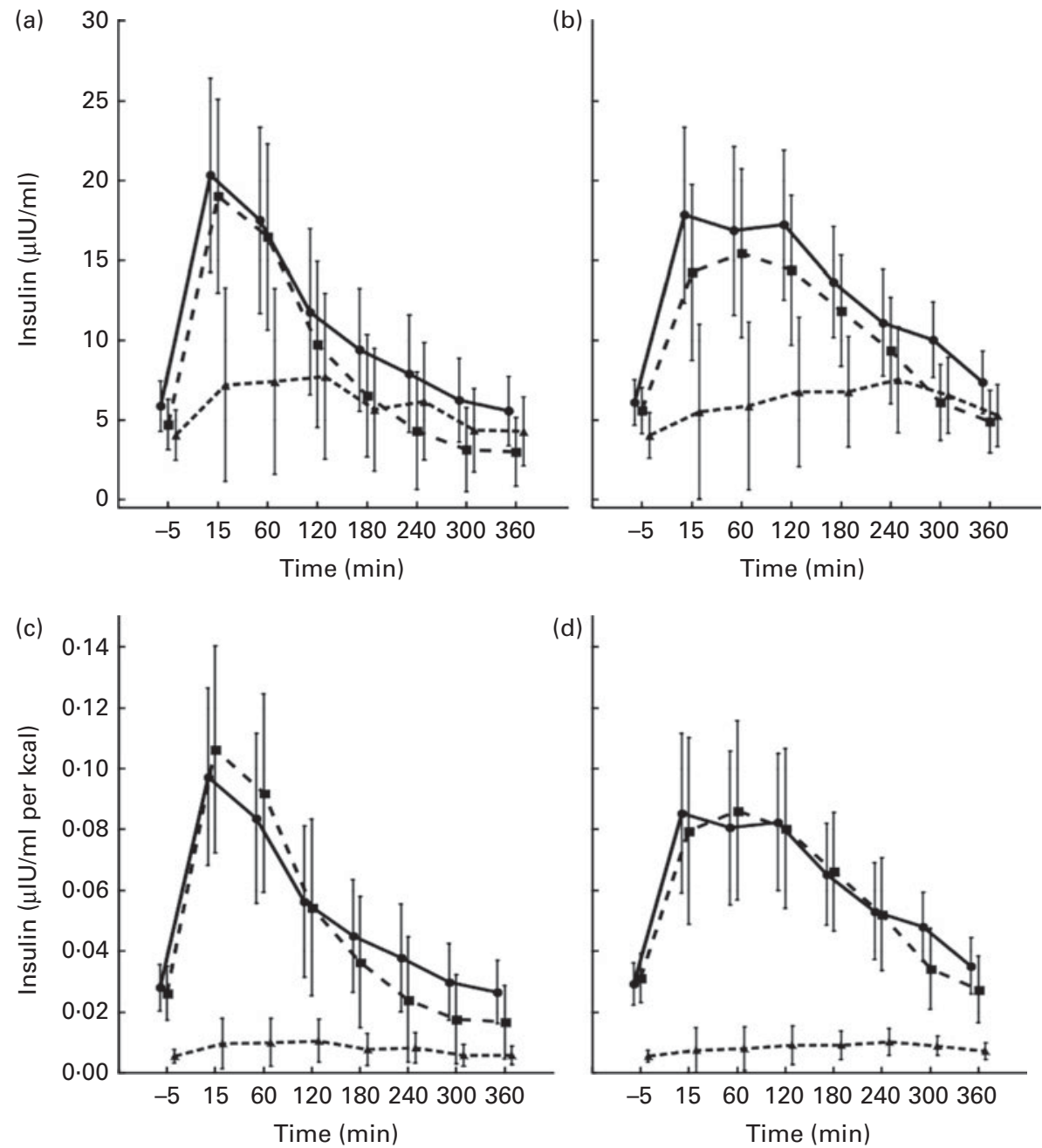

Fig. 3. Serum insulin concentrations before and during a $6 \mathrm{~h}$ period after consumption of the high-carbohydrate (-更), high-protein (meals in (a, c) normal-weight subjects $(n 9)$ and (b, d) obese subjects ( $n$ 11). (a, b) Row and (c, d) energy-adjusted data.

the $\mathrm{AUC}_{\text {total GIP }}$ value was decreased after consumption of the carbohydrate test meal compared with that of the fatty test meal. Furthermore, the $\mathrm{AUC}_{\text {total GIP }}$ value was decreased after ingestion of the protein test meal compared with the fatty test meal in both groups (Table 2). Additionally, the $\mathrm{AUC}_{\text {total GIP }}$ value was lower in obese women than in normal-weight women after consumption of all the test meals (all $P<0 \cdot 05$; Fig. 5).

Effect of the test meals on the levels of hormone release after conversion for consumed energy

The $\mathrm{AUC}_{\text {total insulin }}$ value in both groups was increased after consumption of the protein and carbohydrate test meals compared with the fatty test meal; however, it was similar after ingestion of the protein and carbohydrate test meals (Table 2). There were no significant differences in the values of $\mathrm{AUC}_{\text {total insulin }}$ between the obese and normal-weight women for any of the test meals consumed (Fig. 3).

$\mathrm{AUC}_{\text {total GLP-1 }}$ in the obese group was more increased after protein and carbohydrate than fatty and after protein than carbohydrate test meal consumption. In the normal-weight group, $\mathrm{AUC}_{\text {total GLP-1 }}$ value was increased after consumption of the protein and carbohydrate test meals compared with that of the fatty test meal; however, it was similar after ingestion of the protein and carbohydrate test meals (Table 2). The AUC $_{\text {total GLP-1 }}$ value was significantly decreased only after ingestion of the fatty test meal in obese women compared with normal-weight women $(P<0 \cdot 05$; Fig. 4).

The $\mathrm{AUC}_{\text {total GIP }}$ value in both groups was more increased after than protein and carbohydrate fatty test than fatty test meal consumption, but similar after protein and carbohydrate ingestion (Table 2). The $\mathrm{AUC}_{\text {total GIP }}$ value was significantly decreased only after ingestion of the protein test meal in obese women compared with normal-weight women $(P<0.05$; Fig. 5)

\section{Associations between intestinal hormones and the sensation of satiety and hunger}

After consumption of the fatty meal, a significant positive correlation between the maximum sensation of satiety and 

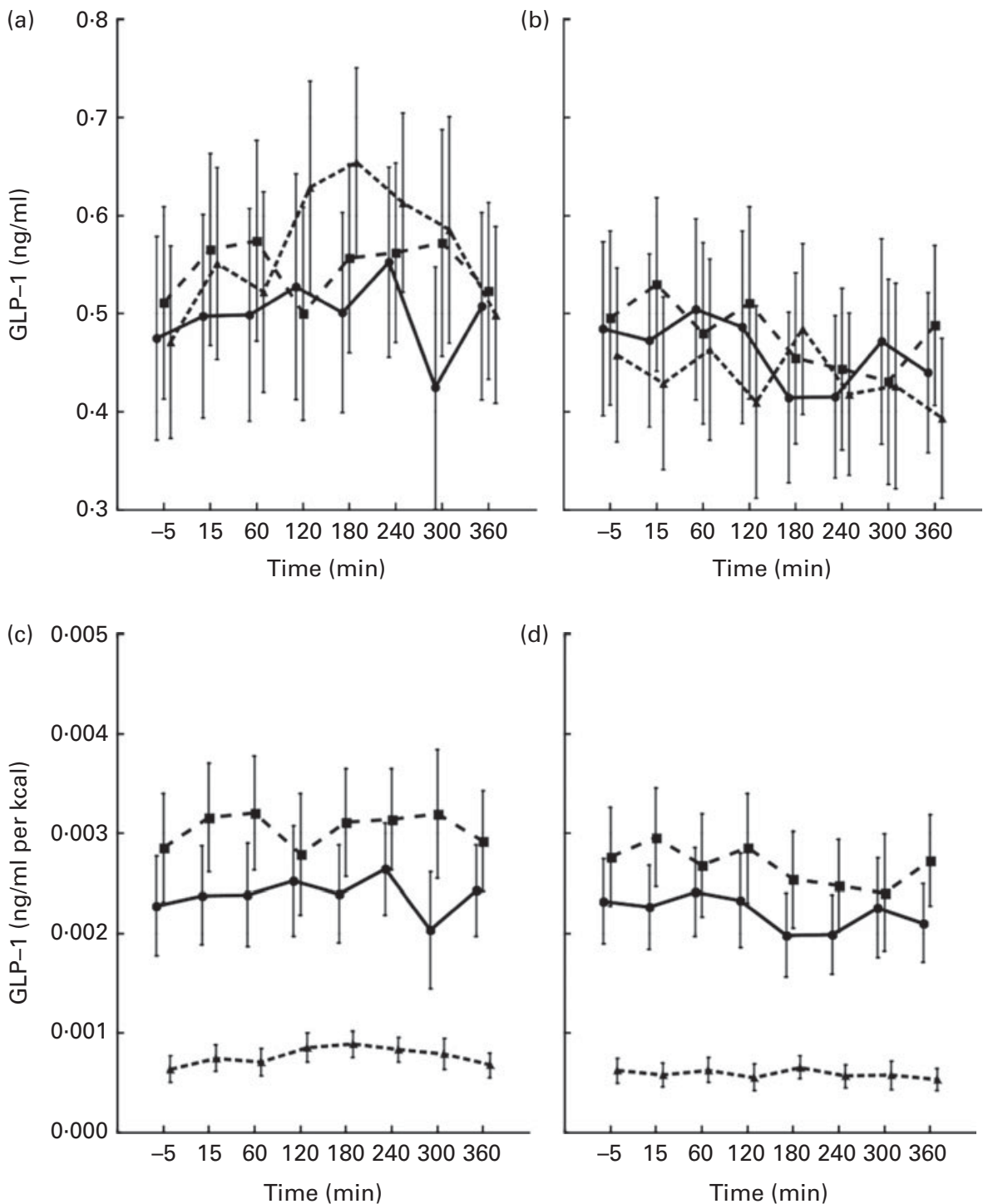

Fig. 4. Plasma glucagon-like peptide-1 (GLP-1) concentrations before and during a $6 \mathrm{~h}$ period after consumption of the high-carbohydrate (- $\mathbf{-}$-), high-protein (- $-\mathbf{-}$-)

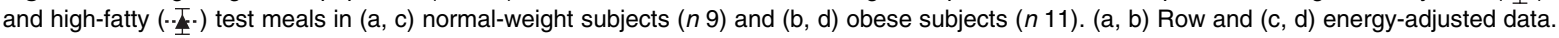

the $\mathrm{AUC}_{\text {total GLP-1 }}$ value $(R 0.91 ; P<0.001)$ in the obese group and that between the minimum sensation of hunger and the $\mathrm{AUC}_{\text {total GLP-1 }}$ value $(R \quad 0.83 ; P<0.01)$ in the normalweight women were observed.

When the postprandial satiety and hunger sensation was converted for consumed meal energy after ingestion of the carbohydrate and protein test meals in the obese group, a positive correlation between the $\mathrm{AUC}_{\text {satiety }}$ and $\mathrm{AUC}_{\text {total insulin }}$ values ( $R$ 0.64; $P<0.05$ and $R 0.68 ; P<0.05$, respectively) was found. However, after consumption of the carbohydrate test meal, a negative correlation between the $\mathrm{AUC}_{\text {hunger }}$ and AUC $\left._{\text {total insulin values }(} R-0.66 ; P<0.05\right)$ was observed in the normal-weight group. Moreover, after ingestion of the fatty test meal, a positive correlation between the $\mathrm{AUC}_{\text {hunger }}$ and AUC $_{\text {total GLP-1 }}$ values $(R \quad 0.62 ; P<0.05)$ in the obese group and that between the $\mathrm{AUC}_{\text {satiety }}$ and $\mathrm{AUC}_{\text {total insulin values }}$ ( $R 0.71 ; P<0.05)$ in the normal-weight group were observed.

\section{Discussion}

This is the first study to assess the influence of high-carbohydrate, high-protein and high-fat test meals that are likely to be normally consumed on the postprandial activity of the incretin axis, insulin secretion and satiety or hunger sensation in obese and normal-weight women.

Fasting satiety sensation in both study groups was similar during all the study days when the test meals were administered. However, it should be emphasised that fasting satiety sensation was significantly higher and fasting hunger sensation was significantly lower in obese women than in normal-weight women. This may be due to the effect of long-term improper eating habits.

As the perception of the subjective sensation of satiety could be affected by meal visualisation and the awareness of its quantity, the participants were not informed about the mass of the test meal. All the meals had the same mass and 

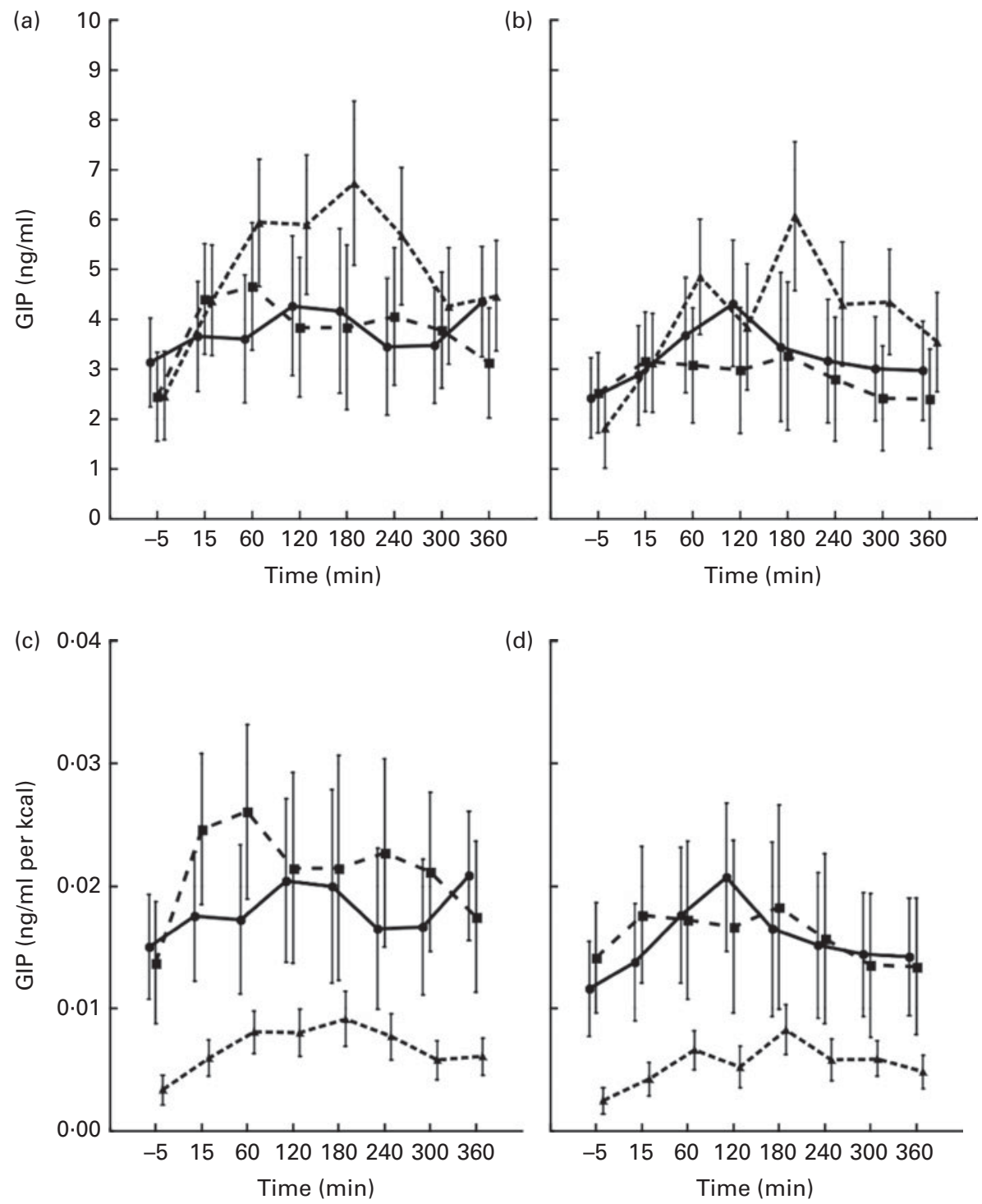

Fig. 5. Plasma glucose-dependent insulinotropic polypeptide (GIP) concentrations before and during a $6 \mathrm{~h}$ period after consumption of the high-carbohydrate

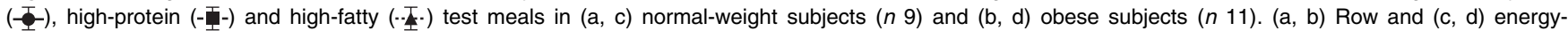
adjusted data.

were served in the same dish. The decision for administration of the test meals with the equal mass, but not volume or energy content, was due to technical difficulties in maintaining a similar volume and energy content of the solid test meals with the predominant amount of various macronutrients. Maintaining the same energy content of the test meals would result in a very small volume and mass of the fatty meal that could affect the subjective sensation of satiety even more than energy density. It should also be noted that the results of previous studies did not establish a consensus on which test meal parameter has the greatest impact on postprandial subjective sensation of satiety. Some studies have shown that energy content has the greatest impact ${ }^{(15)}$, while others have suggested meal volume ${ }^{(16)}$ as well as the meal texture and portion size ${ }^{(17)}$ as playing the predominant role. The present results partially support the latter findings because the mean maximum satiety after ingestion of the carbohydrate, protein and fatty test meals was achieved in a similar time in both obese and normal-weight groups. Moreover, it should be emphasised that the analysis of the changes in sensation of satiety corrected for energy consumed did not affect the results. There was no difference in the time to achieve the mean maximum sensation of satiety after consumption of all the test meals between the obese and normal-weight women. Novel important results of the present study are the differences between the study groups in the time to achieve the minimum sensation of hunger after ingestion of the carbohydrate meal compared with the protein or fatty meal. The time to achieve the minimum sensation of hunger was shorter in obese women and longer in normal-weight women, while it was similar after consumption of the protein and fatty meals in both the obese and normal-weight groups. 
In the obese group, the $\mathrm{AUC}_{\text {satiety }}$ value was significantly increased after ingestion of the fatty test meal compared with the protein and carbohydrate test meals. However, in the normal-weight group, a higher $\mathrm{AUC}_{\text {satiety }}$ value was observed only after consumption of the fatty test meal than the carbohydrate meal. Interestingly, in both study groups, the $\mathrm{AUC}_{\text {hunger }}$ value did not differ after ingestion of all the test meals. It should also be stressed that both $\mathrm{AUC}_{\text {satiety }}$ and $\mathrm{AUC}_{\text {hunger }}$ values after consumption of the carbohydrate and fatty test meals in the obese and normal-weight groups were similar. However, the $\mathrm{AUC}_{\text {satiety }}$ value was low after consumption of the protein test meal and the $\mathrm{AUC}_{\text {hunger }}$ value was high in obese women. These results are in accordance with those described by Cecil et $a l^{(18)}$, showing that ingestion of a high-fat soup suppressed hunger, induced fullness and slowed gastric emptying more than a high-carbohydrate soup and also tended to be more effective at reducing energy intake from the test meal. However, these authors have also revealed that orosensory stimulation induced by nutrients plays an important role in the regulation of appetite. In this context, we hypothesised that lower sensation of satiety after the protein meal in obese women than in normal-weight women is the consequence of differences in orosensory stimulation. The role of the palatability of the test meal but not energy consumed has also been confirmed by another study ${ }^{(19)}$. In addition, it should be emphasised that the analysis of the changes in postprandial sensation of satiety and hunger corrected for consumed energy in the present study did not affect the results.

In the present study, fasting serum insulin levels in obese and normal-weight women were similar. In accordance with the results of a previously published study ${ }^{(20)}$, we observed a lower impact of fatty meals compared with carbohydrate meals on the postprandial insulin response in both groups independent of energy consumed. It is interesting to note that only in normal-weight women, the intake of the carbohydrate meal being stronger than the protein meal stimulated the postprandial insulin response, while in obese women, the postprandial insulin response was higher after the ingestion of the protein meal than the fatty meal. However, after correcting these data for energy consumed, a higher postprandial insulin response after the intake of the protein meal compared with the fatty meal was observed in both study groups. In addition, it should be emphasised that the postprandial insulin response was significantly higher only after ingestion of the carbohydrate test meal in obese women than in normal-weight women. However, after correcting these data for energy consumed, these differences disappeared. Thus, the present results suggest that the postprandial insulin response is dependent on consumed energy only after the intake of the protein meal in the normal-weight group.

In contrast to previous studies, we did not observe any differences in fasting plasma GLP-1 levels between obese and normal-weight women ${ }^{(21)}$. Furthermore, an attenuated postprandial GLP-1 response after ingestion of the mixed meal has been found in obese subjects ${ }^{(6,10-12)}$. However, we observed an attenuated postprandial GLP-1 response after consumption of the fatty test meal in both study groups, independent of energy consumed. However, after correcting these data for energy consumed, a lower postprandial GLP-1 response after the intake of the carbohydrate meal than that of the protein meal was found only in the obese group. These results are in line with those reported by Ranganath et $a l .{ }^{(21)}$, indicating that the attenuated response was observed in the obese group only after the ingestion of a carbohydrate meal. Moreover, Ranganath et al. ${ }^{(21)}$ suggested that the factor that inhibits the postprandial GLP-1 release after consumption of fatty meals is the high level of circulating NEFA. Thus, fatty test meals of different compositions and varied postprandial circulating NEFA levels may affect the GLP-1 release to a different extent. This hypothesis is supported by the results obtained by Maffeis et al. ${ }^{(22)}$ who showed that a meal with a higher fat content than with a lower fat level stimulates the postprandial GLP-1 response in obese boys. Thus, we suggest that the duration of obesity and consumption long-term of a high-fat diet impair the postprandial GLP-1 response after the intake of a high-fat meal.

We failed to find, as described previously, a stronger postprandial GLP-1 stimulation by carbohydrate meals in both obese and normal-weight women ${ }^{(23)}$. Perhaps this is due to the different types of carbohydrates used in the test meals. This hypothesis is supported by the results of a previously published study revealing different GLP-1 responses after the ingestion of various protein ${ }^{(2)}$ and $\mathrm{fat}^{(24)}$ meals. In accordance with these results, Soenen \& Westerterp-Plantenga ${ }^{(25)}$ observed a similar effect of carbohydrate and protein meals on the postprandial GLP-1 response in normal-weight subjects. Furthermore, it has been reported that intake of semi-skimmed milk being stronger than sweetened soft drink stimulates the GLP-1 response in obese individuals ${ }^{(4)}$. The results support the above-described hypothesis of the present study that attenuation of the postprandial GLP-1 response is associated with the duration of obesity and is its consequence.

As mentioned previously(26), we found similar fasting plasma GIP levels in obese and normal-weight subjects before administration of the protein meal. In the two other days (before the carbohydrate and fatty test meals), fasting plasma GIP levels were lower in the obese group, suggesting a high level of variability in GIP secretion and the long-term effects of food intake on the previous day.

In the present study, the postprandial GIP response in obese women was similar after consumption of the carbohydrate, protein and fatty test meals. However, in normalweight women, consumption of the carbohydrate meal being less than that of the fatty meal stimulated the postprandial GIP response. However, after correcting for energy consumed, both carbohydrate and protein meals increased the postprandial GIP response strongly than the fatty meal, and the response was similar after consumption of the carbohydrate and protein meals in both obese and normal-weight women. These results contradict those obtained by Elliot et $a l^{(27)}$, revealing a similar effect of carbohydrate and fatty meals on the postprandial GIP response in young healthy men, while protein meals exhibited only a minimal effect. In addition, an increase in the GIP response after the intake 
of a high-fat meal compared with a carbohydrate meal has been described in obese subjects before and after weight loss ${ }^{(28)}$, type 2 diabetics and healthy subjects ${ }^{(22)}$. It has also been reported that intake of semi-skimmed milk being stronger than that of sweetened soft drink stimulates the GIP response in obese subjects ${ }^{(5)}$. The differences are difficult to explain because Ebert et $a l .{ }^{(29)}$ revealed that in obese individuals, the GIP response is associated with a higher meal energy content and meal volume. However, in the present study, the effect of a high-energy meal was associated with a lower postprandial GIP response independent of body mass. Thus, the present results do not support the hypothesis reported by Ebert et al. ${ }^{(29)}$ suggesting that it is the effect of an attenuated gastric emptying rate after the intake of a fatty meal in the obese group. However, it cannot be ruled out that the differences are the consequences of various carbohydrates and fat used to prepare test meals and different methods used to determine the concentration of GIP.

The normal $^{(6,26)}$, increased $^{(27)}$ or attenuated $^{(29)}$ postprandial GIP response was described in obese subjects. In the present study, the postprandial GIP response was attenuated in obese women compared with normal-weight women after ingestion of all the test meals. However, after correcting for energy consumed, the lower postprandial GIP response in obese women was observed only after ingestion of the protein meal.

We did not observe an association between BMI and the postprandial GIP response. Thus, the attenuated postprandial GIP response seems to be an early defect of the incretin axis in obese subjects and a potential mechanism preventing the increased postprandial glucagon release during the development of insulin resistance partially dependent on energy and macronutrient intakes. Moreover, we suggest that attenuated postprandial GIP response is influenced by the habitual diet composition and energy balance as well as the duration of obesity $^{(24)}$.

It should be emphasised that the postprandial GLP-1 response was associated with the maximum sensation of satiety in obese women and with the minimum sensation of hunger in the normal-weight group only after ingestion of the fatty test meal. However, after correction of the postprandial sensation of satiety and hunger for meal energy consumed, the postprandial sensation of satiety was proportional to the insulin response after ingestion of the carbohydrate and protein meals in obese women, while postprandial sensation of hunger was inversely proportional to the insulin response after consumption of the carbohydrate meal in the normalweight group. Moreover, after consumption of the fatty meal, the postprandial sensation of hunger was proportional to the GLP-1 response in obese women, while the postprandial sensation of satiety was proportional to the insulin response in normal-weight women. It suggests that insulin and GLP-1 are only some of the factors influencing postprandial satiety fullness. In addition, the differences between the obese and normal-weight women indicate that visual and orosensory stimulation as well as individual attitude to the meal play an important role in this partially subjective sensation. This hypothesis is supported by the results obtained by Lemmens et al. ${ }^{(30)}$, revealing that circulating insulin and gut hormone levels explained $40-70 \%$ of the variation in visual analogue scale scores.

The limitation of the present study is the size of the enrolled groups and the enrolment of women exclusively. As we did not include men in the study, the analysed group was more homogeneous. The different energy contents of the test meals and the absence of the test meals with a high fibre content, as well as the lack of the assessment of daily energy consumption after each test meal and the determination of gastric empting are further limitations of the study. Furthermore, the test meals were not administered in random order, as we expected that the fatty test meal would discourage normal-weight women from continuing to participate in the study. Therefore, this meal was served last. Moreover, AUC is only a rough estimation of the integrated changes in plasma GLP-1 and GIP levels, due to long intervals between blood sampling collections and the possible pulsatile GLP-1 and GIP release. Furthermore, peripheral plasma GLP-1 level may not be an adequate measure of the GLP-1 release because it has been shown that about $50 \%$ of the newly secreted GLP-1 from the intestinal L-cells is metabolised when passing from the intestinal stroma into the capillary bed ${ }^{(31)}$.

\section{Conclusions}

The findings of the present study suggest that: (1) subjective factors such as visual and orosensory stimulation as well as individual attitude to the meal, not assessed in the present study, are more important than meal energy and macronutrient contents for postprandial sensation of satiety and hunger; (2) satiety sensation after consumption of carbohydrate and protein meals in obese women is related to the postprandial insulin response, while it is related to the postprandial GLP-1 release after consumption of a fatty meal; (3) the postprandial GIP release does not influence satiety and hunger sensation in both obese and normal-weight women; (4) the reduced GLP-1 release after consumption of a fatty meal in obese women may explain the impaired sensation of satiety; (5) the impaired postprandial GIP release may be the early indicator of incretin axis dysfunction in obese women.

\section{Acknowledgements}

The authors thank Maria Bożentowicz-Wikarek and Aniceta Brzozowska for their assistance and technical support, Grażyna Wrosz for preparing the test meals and Mike Smertka, for language corrections. The study was funded by the National Science Center (project no. 4566/B/P01/2010/39).

The authors' contributions are as follows: T. W. conducted the experiment, collected the data and wrote the manuscript; J. C. was involved in data analyses and helped in the drafting of the manuscript; A. O. participated in the design of the study and performed the statistical analysis; M. O.-G. conceived the study, participated in its design and coordination and helped in the drafting of the manuscript. All authors read and approved the final manuscript.

The authors have no conflict of interest to disclose. 


\section{References}

1. Sacks FM, Bray GA, Carey VJ, et al. (2009) Comparison of weight-loss diets with different compositions of fat, protein, and carbohydrates. $N$ Engl J Med 360, 859-873.

2. Poppitt SD, McCormack D \& Buffenstein R (1998) Short-term effects of macronutrient preloads on appetite and energy intake in lean women. Physiol Behav 64, 279-285.

3. Bowen J, Noakes M \& Clifton PM (2006) Appetite regulatory hormone responses to various dietary proteins differ by body mass index status despite similar reductions in ad libitum energy intake. J Clin Endocrinol Metab 91, 2913-2919.

4. Pawlak DB, Ebbeling CB \& Ludwig DS (2002) Should obese patients be counseled to follow a low-glycaemic index diet? Yes. Obes Rev 3, 235-243.

5. Maersk M, Belza A, Holst JJ, et al. (2012) Satiety scores and satiety hormone response after sucrose-sweetened soft drink compared with isocaloric semi-skimmed milk and with non-caloric soft drink: a controlled trial. Eur J Clin Nutr 66, 523-529.

6. Verdich C, Toubro S, Buemann B, et al. (2001) The role of postprandial releases of insulin and incretin hormones in meal-induced satiety-effect of obesity and weight reduction. Int J Obes 25, 1206-1214.

7. Näslund E, Barkeling B, King N, et al. (1999) Energy intake and appetite are suppressed by glucagon-like peptide-1 (GLP-1) in obese men. Int J Obes Relat Metab Disord 23, 304-311.

8. Turton MD, O'Shea D, Gunn I, et al. (1996) A role for glucagon-like peptide- 1 in the central regulation of feeding. Nature 379, 69-72.

9. Rotondo A, Janssen P, Mulè F, et al. (2012) Effect of the GLP-1 analog liraglutide on sensation and gastric sensorimotor function during nutrient-drink ingestion. Int $J$ Obes (Lond) 37, 693-698.

10. Nauck MA (2009) Unraveling the science of incretin biology. Eur J Intern Med 20, Suppl. 2, S303-S308.

11. Raben A, Andersen HB, Christensen NJ, et al. (1994) Evidence for an abnormal postprandial response to a high-fat meal in women predisposed to obesity. Am J Physiol 267, E549-E559.

12. Raben A, Tagliabue A, Christensen NJ, et al. (1994) Resistant starch: the effect on postprandial glycemia, hormonal response, and satiety. Am J Clin Nutr 60, 544-551.

13. Daousi C, Wilding JP, Aditya S, et al. (2009) Effects of peripheral administration of synthetic human glucose-dependent insulinotropic peptide (GIP) on energy expenditure and subjective appetite sensations in healthy normal weight subjects and obese patients with type 2 diabetes. Clin Endocrinol (Oxf) 71, 195-201.

14. Raben A, Tagliabue A \& Astrup A (1995) The responsibility of subjective appetite scores. Br J Nutr 73, 517-530.

15. Kirkmeyer SV \& Mattes RD (2000) Effects of food attributes on hunger and food intake. Int J Obes Relat Metab Disord 24, 1167-1175.

16. Norton GN, Anderson AS \& Hetherington MM (2006) Volume and variety: relative effects on food intake. Physiol Behav $\mathbf{8 7}$, $714-722$
17. Leidy HJ, Apolzan JW, Mattes RD, et al. (2010) Food form and portion size affect postprandial appetite sensations and hormonal responses in healthy, nonobese, older adults. Obesity (Silver Spring) 18, 293-299.

18. Cecil JE, Francis J \& Read NW (1999) Comparison of the effects of a high-fat and high-carbohydrate soup delivered orally and intragastrically on gastric emptying, appetite, and eating behaviour. Physiol Behav 67, 299-306.

19. Yeomans MR, Lee MD, Gray RW, et al. (2001) Effects of testmeal palatability on compensatory eating following disguised fat and carbohydrate preloads. Int $J$ Obes Relat Metab Disord 25, 1215-1224.

20. Collier G, McLean A \& O'Dea K (1984) Effect of co-ingestion of fat on the metabolic response to slowly and rapidly absorbed carbohydrates. Diabetologia 26, 50-54.

21. Ranganath LR, Beety JM, Morgan LM, et al. (1996) Attenuated GLP-1 secretion in obesity: cause or consequence? Gut $\mathbf{3 8}$, 916-919.

22. Maffeis C, Surano MG, Cordioli S, et al. (2010) A high-fat $v$ s. a moderate-fat meal in obese boys: nutrient balance, appetite, and gastrointestinal hormone changes. Obesity (Silver Spring) 18, 449-455.

23. Rijkelijkhuizen JM, McQuarrie K, Girman CJ, et al. (2010) Effects of meal size and composition on incretin, alphacell, and beta-cell responses. Metabolism 59, 502-511.

24. Thomsen C, Rasmussen O, Lousen T, et al. (1999) Differential effects of saturated and monounsaturated fatty acids on postprandial lipemia and incretin responses in healthy subjects. Am J Clin Nutr 69, 1135-1143.

25. Soenen S \& Westerterp-Plantenga MS (2007) No differences in satiety or energy intake after high-fructose corn syrup, sucrose, or milk preloads. Am J Clin Nutr 86, 1586-1594.

26. Sarson DL, Kopelman PG, Besterman HS, et al. (1983) Disparity between glucose-dependent insulinotropic polypeptide and insulin response in obese man. Diabetologia 25, 386-391.

27. Elliott RM, Morgan LM, Tredger JA, et al. (1993) Glucagonlike peptide-1 (7-36)amide and glucose-dependent insulinotropic polypeptide secretion in response to nutrient ingestion in man: acute post-prandial and 24-h secretion patterns. J Endocrinol 138, 159-166.

28. Jones IR, Owens DR, Luzio SD, et al. (1989) Obesity is associated with increased post-prandial GIP levels which are not reduced by dietary restriction and weight loss. Diabetes Metab (Paris) 15, 11-22.

29. Ebert R \& Creutzfeldt W (1992) Gastric inhibitory polypeptide (GIP) hypersecretion in obesity depends on meal size and is not related to hyperinsulinemia. Acta Diabetol Lat 26, $1-15$.

30. Lemmens SG, Martens EA, Kester AD, et al. (2011) Changes in gut hormone and glucose concentrations in relation to hunger and fullness. Am J Clin Nutr 94, 717-725.

31. Hansen L, Deacon CF, Ǿrskov C, et al. (1999) Glucagon-like peptide-1-(7-36)amide is transformed to glucagon-like peptide-1-(9-36)amide by dipeptidyl peptidase IV in the capillaries supplying the $\mathrm{L}$ cells of the porcine intestine. Endocrinology 141, 5356-5363. 